\title{
Configurações
}

Revista de sociologia

$21 \mid 2018$

Justiça, Instituições, Interlocuções

\section{Bem-vindos à Fábrica das Frustrações!: a (anti)linguagemprisional}

Welcome to the Factory of Disappointments!: The prison (anti)language

Bienvenus à l'Usine des Frustrations!: l'(anti)langage carcéral

José Eduardo Lopes Gonçalves

\section{CpenEdition}

\section{Journals}

Edição electrónica

URL: http://journals.openedition.org/configuracoes/5099

DOI: $10.4000 /$ configuracoes.5099

ISSN: 2182-7419

\section{Editora}

Centro de Investigação em Ciências Sociais

Edição impressa

Paginação: 28-42

ISSN: 1646-5075

\section{Refêrencia eletrónica}

José Eduardo Lopes Gonçalves, « Bem-vindos à Fábrica das Frustrações!: a (anti)linguagemprisional », Configurações [Online], 21 | 2018, posto online no dia 30 junho 2018, consultado o 19 abril 2019. URL http://journals.openedition.org/configuracoes/5099; DOI : 10.4000/configuracoes.5099 
Gonçalves, José Eduardo Lopes - Bem-vindos à Fábrica das Frustrações!: a (anti)linguagem prisional. Configurações, vol. 21, 2018, pp. 28-42.

\title{
Bem-vindos à Fábrica das Frustrações!: a (anti)linguagem prisional
}

\section{JOSÉ EDUARDO LOPES GONÇALVES*}

Faculdade de Letras da Universidade de Coimbra/ Faculdade de Economia da Universidade de Coimbra/ Centro de Estudos Sociais - Universidade de Coimbra

\section{Resumo}

Este artigo explora os poemas de pessoas em reclusão do ponto de vista da pesquisa poética. Neste sentido, com base nos poemas-testemunho recolhidos nas prisões de Coimbra (EPC) e de Santa Cruz do Bispo Feminino (EPSCBF), procurar-se-á demonstrar as potencialidades da pesquisa poética para o estudo das realidades prisionais, através da análise crítica dos textos. Para tal, partimos dos princípios de que o poema é um rizoma e que o/a poeta é um/a artesão/ã da língua(gem), com o intuito de evidenciar que os poemas-testemunho são uma ferramenta produtiva para a desconstrução do discurso prisional.

Palavras-chave: prisão, discursos, pesquisa poética, poemas-testemunho.

\begin{abstract}
Welcome to the Factory of Disappointments!: The prison (anti)language

This article explores inmates' poems through a poetic inquiry approach seeking an argumentative discussion on the potentialities of poetic insights that examine prison context realities. This research study focuses on the poetic and thematic analyses of witness poems written by inmates from prisons in Coimbra and a female incarceration facility located in Santa Cruz do Bispo, Portugal. In order to demonstrate that witness poems are a powerful tool to deconstruct the prison language, one should consider poetics as a rhizome and poets as language craftsmen.
\end{abstract}

Keywords: prison, discourses, poetic inquiry, poetry of witness.

*E-mail: josegoncalves@ces.uc.pt 


\section{Résumé}

\section{Bienvenus à l'Usine des Frustrations !: l'(anti)langage carcéral}

Cet article explore les poèmes des personnes en détention du point de vue de la recherche poétique. Dans ce sens, à partir des poèmes-témoignages recueillis dans les prisons de Coimbra et de Santa Cruz do Bispo Feminino, l'objectif est de démontrer le potentiel de la recherche poétique pour l'étude des réalités carcérales grâce à l'analyse critique des textes. Pour cela, il faudra partir du principe que le poème est un fondement et que le/la poète est un artisan de la langue/du langage, dans le but de mettre en évidence le rôle des poèmes-témoignage en tant qu'outil productif pour la déconstruction du langage carcéral.

Mots-clés: prison, discours, recherche poétique, poèmes-témoignage.

\section{Introdução}

Os três andamentos principais que estruturam este artigo partem de poemas resultantes de oficinas de escrita criativa realizadas no EPC, em 2013, e no EPSCBF em 2015. Estas oficinas, desenvolvidas por mim e por iniciativa própria ainda durante a licenciatura em Português, surgem na sequência de outros projetos poéticos que vinha dinamizando com comunidades silenciadas.

A oficina em Coimbra decorreu durante um mês, tendo cada sessão a duração de aproximadamente duas horas, duas vezes por semana na parte da tarde. Já a de EPSCBF realizou-se ao longo de uma intensiva semana, duas horas em cada manhã e em regime de substituição das aulas escolares do $9^{\circ}$ ano. Aspeto este que assinala logo uma diferença entre os projetos, na medida em que enquanto que no EPSCBF a turma foi escolhida pela instituição, em Coimbra as oficinas eram abertas e, por isso, tiveram sempre participantes diferentes e de diversos níveis de escolaridade. Outra diferença entre os projetos é que o primeiro tinha como objetivo final a construção e apresentação de uma performance aberta, tanto à comunidade intramuros quanto à extramuros, enquanto que no EPSCBF trabalhámos no sentido de construir uma fanzine. Contudo, a meio de ambos os processos surgiu a possibilidade de elaborar uma obra literária, pelo que daí resultou a edição do Poesia há. Solta! (A Equi, 2013), e do Mulheres Guerreiras - A Caminho da liberdade (Gonçalves, 2017), cujos poemas servirão de base para este artigo.

Apesar dos distintos objetivos finais ambos os projetos tiveram uma metodologia semelhante e altamente flexível. As sessões começaram sempre com a leitura de textos de autoria própria. Implicaram, sobretudo, a desconstrução do significado de poesia a partir da interpretação de um conjunto de poemas pré-selecionados - dos mais canónicos aos mais experimentais, e cuja dinâmica estimulou a realização de exercícios de escrita criativa. Pautadas por uma lógica horizontal, democrática e colaborativa, as sessões deram primazia à vontade das pessoas em detrimento dos objetivos diários das oficinas, interessando mais o debate suscitado pelos textos do que o plano das sessões. Tal 
como nos diz Buzz Alexander (2011), "It is essential that I do not have in mind something that must be asked, said, or known in a given session" (p. 167), sendo mais importante abrir espaço a um mútuo trânsito de informação entre o/a dinamizador/a do projeto e os/as participantes, permitindo que ambas as partes se tornem criadores/as de um outro conhecimento (Pompa, 2011).

Neste sentido, sugere-se pensar, desde logo, na diferença entre projeto poético e pesquisa poética, uma vez que o primeiro não apresenta necessariamente uma preocupação analítica dos fenómenos sociais com que se depara, sendo este um fator que, por sua vez, é basilar em qualquer tipo de investigação dentro das ciências humanas e sociais. Assim, esta distinção é crucial para a compreensão deste artigo, na medida em que a partir de textos de dois projetos poéticos intentar-se-á justificar a pertinência do desenvolvimento da pesquisa poética para o estudo das realidades prisionais. Do ponto de vista pessoal, esta é a distinção que caracteriza o meu percurso académico que agora, no doutoramento, se ocupa do estudo de contextos prisionais a partir, essencialmente, dos poemas de pessoas privadas da liberdade.

Relativamente à estrutura deste artigo, o primeiro andamento situa as noções de escrita criativa, de poesia, de poeta e de poema de modo a construir a pauta de base para os andamentos seguintes. No segundo, falaremos sobre a pesquisa poética e a pesquisa baseada em arte, de modo a enquadrar a análise e a interpretação dos poemas-testemunho, que se fará no último andamento e antes das considerações finais Iniciaremos com o poema de António Simões (A Equi, 2013: 32):
Há show no E.P.
batem às portas
gritam "Calem-se!"
é alegria surda
de cada; muitos
é esperança
e o princípio do fim
no E.P. sonha-se
a esperança
o depois
procura-se o sonbo adiado
como uma figura de barro

\section{Escrita criativa, poe sia/ta/ma}

Partindo do étimo poiein, poesia é fazer, compor e criar. Tal como toda a linguagem, a poesia é epistemológica e ontológica (Leggo, 2008), e negá-lo é refutar o papel nuclear do discurso na construção e no condicionamento da experiência humana. Assumindo que "o conceito de identidade não existe fora 
da linguagem e dos poderes que a estruturam" (Capinha 1997: 104), a potencialidade da poesia pode partir do facto de se debruçar sobre a linguagem para a esculpir, e desconstruir, como se de um ofício se tratasse. Neste sentido, a poesia é um instrumento, tal como o microscópio ou a câmara, que permite o surgimento, e o questionamento, de realidades silenciadas e ocultadas que de outra forma não se expressariam (Cahnmann-Taylor, 2009). Ideia esta central para a escola da $\mathrm{L}=\mathrm{A}=\mathrm{N}=\mathrm{G}=\mathrm{U}=\mathrm{A}=\mathrm{G}=\mathrm{E}$ que defende uma noção de poesia enquanto espaço de rutura, que suscite o eclodir de constelações para, dessa forma, "fornecer um lugar para a construção de configurações e factos sociais e imaginativos que, em tudo o resto, são evitados ou ignorados” (Bernstein, 1997: 104).

De acordo com a importância política da poesia (Parini, 2009), os/as poetas são os/as não reconhecidos/as legisladores/as do mundo (Shelley, citado em Orr, 2008), visto serem artesãos/ãs da língua(gem). Se tudo se estrutura na e pela língua(gem), é através da manipulação arqueológica da mesma que o/a poeta tem a capacidade de (re)construir mundos outros e, como tal, o/a poeta aproxima-se da função de um/a cientista (Leggo, 2008; Faulkner, 2009). Relativamente à noção de poema, entende-se que é uma superfície onde se hospedam as constelações, é um espaço de fronteira(s) em que proliferam dinâmicas multivetoriais, uma vez que a missão do texto é reencenar parte do processo de produção que está por detrás, ou que suporta, a identidade pessoal, portanto, social (Andrews, 2001). Interessa ainda salientar que o poema é "um palimpsesto, em que a linguagem sedimentada transparece"1 (Wolff, citado em Prendergast, Leggo, e Sameshima, 2009).Nesta direção, este artigo assume os poemas das pessoas em reclusão como poemas-testemunho (Johnson e Chernoff, 2002), já que nascem na oposição dialética à condição extrema que os tornou necessários (Forché, 1993).

A importância de situar estas noções prende-se ao facto de ter sido este o entendimento que esteve na base das oficinas nos estabelecimentos prisionais, $\mathrm{o}$ que as aproxima da pesquisa de mestrado de Teresa Fonseca (2010) no Centro Educativo dos Olivais, ao ter desenvolvido a escrita criativa como uma metodologia política e social, afastada do modelo comunicativo/ colaborativo de linguagem e preocupada com o reconhecimento de outros territórios silenciados.

\section{Pesquisa poética, pesquisa baseada em arte}

O surgimento da pesquisa baseada em arte perspetiva-se a partir das mudanças operadas no seio académico, nas décadas de 1960-70, uma vez que, através do questionamento dos processos de construção de conhecimento, as fronteiras dos repositórios metodológicos expandiram-se (Leavy, 2015). De acordo com 
Finley (2008), a pesquisa baseada em arte é uma metodologia radical, ética, revolucionária, socialmente responsável, útil para tratar de desigualdades sociais, que expõe opressões e que esboça possibilidades para a transformação social. Assim, a pesquisa baseada em arte cria e habita espaços limiares, formando-se no hífen entre arte e investigação nas ciências sociais (Finley, 2008).

Utilizada em várias áreas desde os anos 80 , a pesquisa poética começa a ser reivindicada na sociologia com o trabalho de Richardson (1993). Contudo, a pesquisa poética continua a ocupar um lugar periférico dentro do paradigma qualitativo (Prendergast et al, 2009) e, como tal, os/as investigadores/as da pesquisa poética sentem, ainda, a necessidade de legitimar a sua abordagem, ao mesmo tempo que têm de enfatizar as virtudes da poesia (Bishop e Willis, 2014). A pesquisa poética visa uma compreensão holística dos fenómenos sociais, é recetiva ao inesperado, permite a revelação do individual e procura possíveis e múltiplas verdades (Rapport e Harthill, 2012). A poesia pode ser integrada de forma parcial, ou na sua totalidade, no desenho desta pesquisa, podendo ser utilizada como meio para a recolha de dados, análise, interpretação e/ou representação dos dados.

A pesquisa poética é um guarda-chuva terminológico, que acolhe os múltiplos termos que se referem a esta metodologia no domínio da pesquisa baseada em arte (Prendergast et al., 2009) e, dentro da sua hibridez, a pesquisa poética pode ser dividida em três categorias, mediante a voz destacada (Prendergast et al., 2009): vox theoria - teórica que explora a literatura sobre a pesquisa poética (Piirto, 2002; Faulkner, 2009; Rapport e Harthill, 2012; Shapiro, 2004; Lahman et al., 2011); vox autobiographia/autoethnographia - reflexiva do/a investigador/a (Furman et al., 2007; Kinsella, 2006; Prendergast, 2013; Hartnett, 2003); vox participare - dos/as participantes, normalmente apresentada como found poems, construídos a partir de dados previamente recolhidos (Richardson, 1993; Pillay, Pithouse-Morgan, e Naicker, 2017; Sjollema e Bilotta, 2016; Bishop e Willis, 2014; Johnson e Chernoff, 2002; Fonseca, 2010). Segundo esta proposta de categorização, este artigo enquadra-se no último grupo ao se centrar na voz das pessoas em reclusão, pelo que é representativo da tendência deste tipo de estudos em serem conduzidos com comunidades marginalizadas (Sjollema e Bilotta, 2016).

Entre os inúmeros questionamentos levantados pela pesquisa poética interessa, aqui, destacar três problemáticas principais: pode a poesia ser considerada como fonte de dados (Shapiro, 2004; Lahman et al., 2011; Furman et al., 2007; Richardson, 1993)? Responder a esta questão implica refletir, sobretudo, sobre a própria pesquisa baseada em arte, na medida em que esta, ao defender a reaproximação da arte com a ciência, insurge-se contra a hegemonia da racionalidade Aristotélica-Cartesiana-Kantiana (Shidmehr, 2014). Nesta direção, considere-se que o objetivo tanto da poesia quanto das ciências sociais é providenciar conhecimento, de modo a abrir espaço para que múltiplas 
realidades se traduzam numa compreensão maiúscula dos fenómenos sociais (Furman et al., 2007; Prendergast et al., 2009; Galvin e Prendergast, 2016; Faulkner, 2009; Richardson, 1993, 2002; Shapiro, 2004; Sjollema e Bilotta, 2016; Bishop e Willis, 2014). Como tal, é significativo o contributo de Shapiro (2004), que assume a possibilidade de se criar um oximoro quando se justapõe os termos poesia e dados.

Seguimos com a seguinte questão: que poesia pode ser considerada pesquisa (Piirto, 2002; Prendergast et al., 2009; Faulkner, 2009)? A dúvida aqui é perceber se a qualidade dos poemas não afeta a eficácia da pesquisa e, concordando-se com esta última autora, o fator nuclear será o objetivo da pesquisa, uma vez que será ele que definirá a investigação, o seu desenho e o seu corpus. Assumindo-se que tudo significa num poema (Leggo, 2008), é necessário extrapolar a dimensão textual, superficial do poema, de modo a que se percorra o seu rizoma - um sistema sem centro, uma espécie de mapa em permanente construção que não cessa de conectar cadeias semióticas e organizações de poder (Deleuze e Guattari, 1986). Por outras palavras, a qualidade poética, estilística, apresenta uma importância relativa para a pesquisa, uma vez que ela não invalida que os poemas sejam bons o suficiente para a investigação ${ }^{2}$.

Através do critério da qualidade estabelece-se o elo entre a dúvida anterior e as seguintes perguntas: quem pode desenvolver esta metodologia? É necessário que o investigador/a seja um/a poeta, ou que tenha conhecimentos específicos sobre a arte poética (Piirto, 2002; Faulkner, 2009; Prendergast et al., 2009; Leggo, 2008)? Estes autores defendem que sim, que tanto investigadores/ as quanto os/as participantes devem manejar a arte poética como se de um ofício se tratasse ou, pelo menos, devem frequentar cursos de escrita criativa, de modo a não hipotecar a pesquisa com a produção de poem-like, ou poemas inferiores (Piirto, 2002). Ou seja, de acordo com esta visão é necessário que a qualidade, a autoridade dos/as intervenientes esteja previamente reconhecida para que a eficácia da pesquisa não seja comprometida.

Para terminar este andamento, note-se que uma das vantagens associada à pesquisa poética prende-se com a capacidade da poesia em evocar uma resposta emotiva do/a leitor/a, todavia, interessa salientar que a pesquisa poética deve ir além da evocação emocional, procurando motivar a ação do/a leitor/a (Dark, 2009). Com isto, partirmos para o terceiro andamento que se preocupará com uma análise crítica, dos poemas-testemunho das pessoas em reclusão. Esta análise crítica do discurso vincula-se à proposta de Blommaert (2005), que defende a maior importância do quadro socio-histórico na construção dos contextos discursivos, em detrimento da mera dimensão linguística radicada no discurso disponível - o aqui e agora. Esta análise persegue, ainda, o remainder 
de Lecercle (1990), um espaço fronteiriço, de excesso, entre a linguagem e o mundo que abre território ao surgimento dos possíveis.

\section{Sobre os poemas-testemunho...}

\section{Poetando ${ }^{3}$}

Preso, represo, preventivo, condenado - esquecido

Olha para o futuro por detrás dos gradões.

Pedido de tratamento humano... indeferido.

Bem-vindos à Fábrica das Frustrações!

Pertence agora à grande Irmandade da Estatística. Oh não!

Olha para lá dos gradões...

Sonhos e projetos já não estão; vão, vão... voltarão?

Bem-vindos à Fábrica das Frustrações!

A chave que usa farda

que dia após dia abre e fecha os gradões,

mais presa do que ele, vê que o fim do turno tarda.

Bem-vindos à Fábrica das Frustrações!

O mano que vagueia, curvado, olhando o chão

à procura dumas passas, em forma de beata

para fumar aos serões

sentado olha para a grade, e espera que o amanhã,

coitado, não lhe bata.

Bem-vindo à Fábrica das Frustrações!

E esse mano que curvado vagueia, olhando o chão

deixou de ser um homem

já não tem nome, não.

Aqui os nomes somem.

860, dirija-se ao gradão.

E com o susto do aviso deixou cair no chão as ilusões.

Não faz mal, mano! Então?!

Bem-vindo à Fábrica das Frustrações!

"Aqui o conceito de igualdade

é um conceito ultrapassado" 
sentencia o Chefe dos Chefes no alto dos seus galões alheio à veracidade

dos sintomas que manifesta, diagnóstico adulterado. Assim é na Fábrica das Frustrações!

No diálogo entre os versos “Bem-vindo à Fábrica das Frustrações” e “Assim é na Fábrica das Frutrações”, Francisco Indigo parece construir um roteiro pelos meandros daquela prisão, como que convidando-nos a observar as suas várias dimensionalidades e silêncios.

A primeira estrofe concorre para um eficaz resumo daquilo que pode representar a experiência do cárcere, sendo flagrante o verso "Preso, represo, preventivo, condenado - esquecido". Repare-se como o diálogo entre a condição de preso e de reincidente, e a de preventivo e de condenado resulta na ênfase, por hífen, de um processo de silenciamento e afastamento social das pessoas que pertencem à rota da exclusão - aquilo a que Rhodes (2001) chamaria a magia da prisão, a capacidade da prisão em fazer desaparecer determinadas franjas sociais. Por outro lado, esse diálogo pode denunciar uma condição de abandono familiar fruto da detenção - que é um dos efeitos da reclusão (Granja, 2017: 47-76), ao mesmo tempo que chama a atenção para a violência da reclusão independentemente da condição em que está, colocando ao mesmo nível o estar preso, o ser reincidente, o estar condenado ou estar em prisão preventiva.

A partir do verso "Sonhos e projetos já não estão; vão, vão... voltarão?" o poeta parece denotar uma certa desconfiança, algo irónica, sobre o discurso da reinserção social. Um outro ponto merece referência no poema: "A chave que usa farda/ (...) mais presa do que ele, vê que o fim do turno tarda". Reportando-se ao guarda-prisional é interessante o reconhecimento dos efeitos nocivos da prisão sobre o mesmo, e embora não seja clara a comparação "mais presa do que ele", o poeta deixa em aberto a possibilidade de pensar que o guarda está mais preso do que os detidos. Dada a ambiguidade, este é um dos casos que justifica o recurso a mais textos do autor, ou a outras técnicas metodológicas, para melhor se alcançar o potencial deste texto. Note-se, ainda, a violência associada aos momentos em "que dia após dia abre e fecha os gradões".

Atentando na quarta estrofe e no facto de haver pessoas "à procura dumas passas, em forma de beata" no chão, podemos pensar no modo como as desiguais condições socioeconómicas se estendem e se perpetuam intramuros. Sob uma outra perspetiva, parece plausível assumir que o "coitado", que só lhe resta esperar de olhos no chão, pode ser uma projeção da própria condição presente ou passada do poeta, até porque é seguida pela referência à perda da identidade ou, nos termos de Goffman (1961), à «mortificação do eu» característica nas prisões. 
A "Fábrica das Frustrações" pode ser, então, o espaço onde os direitos humanos ficam à porta, onde os diagnósticos são adulterados e o uso discricionário de poder é tecido verticalmente, pelo que a leitura do Poetando dá-nos uma imagética que pode constituir uma espécie de ontologia (Kramer, 2016) sobre aquela prisão.

Atentemos, agora, no excerto do poema-testemunho de Lúcia (Gonçalves, 2017: 16):

\section{Estou presa, sim, presa da liberdade \\ Mas ganhei uma liberdade que não \\ tinha e ganbei-a aqui no E.P.}

As palavras de Lúcia caminham no sentido oposto das de Indigo, apresentando-nos a prisão como geradora de liberdade. Destaca-se, desde logo, o facto de, ao contrário do que Foucault (2008) dissera sobre a prisão produzir efeitos homogéneos, as perceções e representações sobre a experiência do cárcere são tão diversas quanto as pessoas que a compõem (Crewe, 2009). Como afirma Johnson e Chernoff (2002), "Inmate poetry has the power to draw our attention to the many different ways a common prison reality may impinge with unique singularity on the lives of convicts" (p.145)Por outro lado, Lúcia deixa em aberto a resposta, por exemplo, às seguintes perguntas: que tipos de liberdade estão em jogo, e o que significa a liberdade para a Lúcia? Se a prisão serve, também, para privar as pessoas da liberdade, de que forma ela constrói liberdade? Estará esta prisão a cumprir a sua missão? Que discursos constrói?

Respostas essas que seriam fundamentais para compreendermos o que representa realmente a reclusão para Lúcia, pelo que as suas palavras deixam-nos num nível de subjetividade que constitui um entrave para a descodificação textual. Porém, se por um lado a poesia no geral é caracterizada pela subjetividade e, por isso, comummente conotada como pouco acessível ou de difícil interpretação, por outro lado, este seria mais um caso em que seria necessário recorrer a mais textos da autora ou a outras técnicas metodológicas, nomeadamente à realização de entrevista. Ou seja, se este texto surgisse no âmbito de uma pesquisa poética e fosse pertinente averiguar as respostas supramencionadas, então o/a investigador/a não poderia ficar-se pela análise deste texto. Vejamos outro exemplo em que a problemática da subjetividade se coloca no texto a colagem \#2 (A Equi, 2013: 22): 


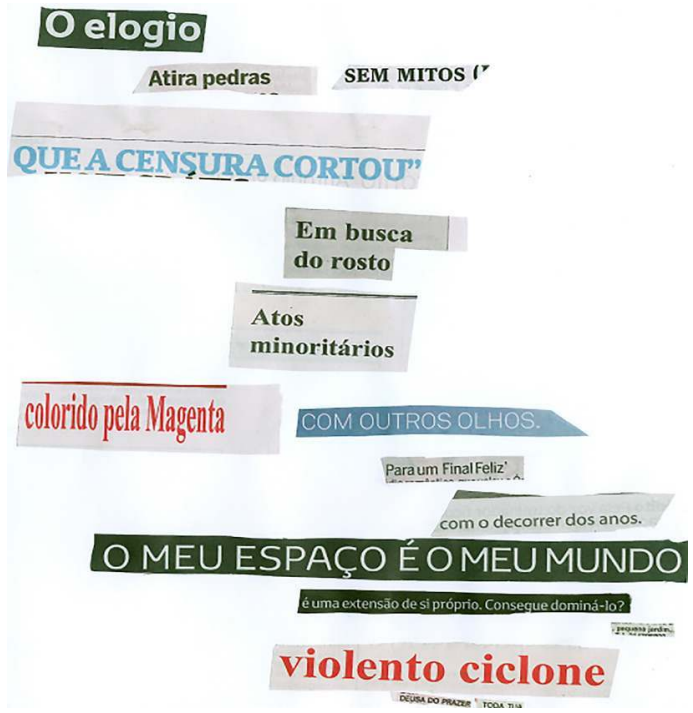

A collage é um exercício de escrita criativa que parte da fragmentação de textos para construir um novo. Neste caso, os poetas recortaram jornais e revistas, e a partir de um conjunto de recortes selecionaram estes fragmentos e elaboraram coletivamente este texto. O exercício da collage é altamente produtivo por desafiar as convenções discursivas, incentivando à liberdade da composição, embora que este texto, e em comparação com outras colagens (A Equi, 2013; Gonçalves, 2017) apresenta uma mancha gráfica relativamente convencional. Uma leitura superficial desta collage retrata as dificuldades levantadas pela ambiguidade e subjetividade textual, já que a aparente falta de coesão e linearidade discursiva insinua uma extração semiótica pouco significativa.

Contudo, considere-se que este poema apresenta a particularidade de ter uma técnica superior de reeducação como elemento daquele grupo, tendo sido a sua vontade estética que imperou fruto de um consentimento imediato pelos restantes membros do grupo. Inserido este dado, obtido através da observação direta, percebemos que a potencialidade deste poema reside na análise do seu contexto e das suas «linhas de fuga» (Deleuze e Guattari, 1986) - linhas que descolam do rizoma para abrir caminhos possíveis para diversas formas de ver o mundo, a linguagem, o sujeito e a identidade. Assim, as linhas de fuga que brotam deste poema podem ser úteis, por exemplo, para problematizar as relações de poder entre o corpo técnico e a população reclusa, nomeadamente porque não houve nenhuma oposição à sugestão da técnica. Neste sentido, podemos assumir que a composição da collage pode ser análoga às formas de 
sociabilização e de organização da comunidade intramuros e, por isso, a collage mostra-se produtiva ao fornecer novas e diferentes formas de pensar sobre os fenómenos (Butler-Kisher, 2008).

A questão que se coloca é, portanto, até que ponto não será necessária a subjetividade textual em contexto de reclusão? Num espaço marcado por um «regime de verdade» (Foucault, 2010) - práticas discursivas dominantes que definem e condicionam as subjetividades individuais - fortemente opressor, como aceder ao «discurso oculto» (Scott, 1990)? A partir deste collage defende-se, então, que na dicotomia entre «discurso público», ou «regime de verdade», e «discurso oculto» ${ }^{4}$ - um conjunto de práticas de resistência, de subversão, uma linguagem não-hegemónica - a subjetividade pode ser um instrumento necessário para mergulhar e desconstruir no globo prisional.

Partimos agora para um último exemplo, resultante do exercício «Cadáver esquisito» que, neste caso (Gonçalves, 2017: 24) - são muitas as variantes que podem ser utilizadas -, consiste num texto coletivo em que as poetas não tiveram acesso ao que as outras escreveram.

Temo que a liberdade se torne um vício.

Tenho saudades meu amor

Quem sou não sei ou sei quem sou.

Eu gosto imenso dos meus filhos.

Começo por te dizer que te tenho um grande amor.

Cada dia que passo dentro desta cadeia a

dor e as saudades alimentam cada vez

mais.

Anseio a minha liberdade.

A ilusão do teu olhar, traz-me muitos

Sonhos, como o sonhar com a minha

liberdade.

Sinto falta da tua pele macia quando

eras um bebé e eu a sentia, amor da

minha vida, paixão por ti sentida.

Considerando que este poema era de tema livre e que as pessoas não sabiam sobre o que as outras escreviam, é interessante constatar uma linearidade discursiva que aponta para a relação entre o amor materno e a reclusão, ou o desejo da liberdade. Como explicar esta aparente linearidade - e aparente porque não sabemos a quem a poeta se dirige em versos como "Tenho saudades meu amor" -, num exercício que explora e se espera uma imprevisibilidade

4 Sobre a relação entre discursos públicos e discursos ocultos produzidos por jovens em contexto de centro educativo, consulte-se a tese de Ana Manso (2016). 
textual? $\mathrm{Na}$ tentativa de encontrar respostas a esta inquietação é útil o conceito de intertextualidade (Kristeva, 1980), que assume os textos não como entidades significantes isoladas, mas antes em relação com outros textos sociais e históricos. Neste sentido, a intertextualidade é produtiva para se problematizar as intersubjetividades que coexistem no cárcere.

Neste terceiro andamento procurou-se demonstrar como os textos das pessoas privadas da liberdade podem abrir caminhos para a desconstrução dos discursos prisionais. Paralelamente, saliente-se que "Writing is the catharsis (...) the door in which they can recreate their life" (Rhodes, 2002: 164) e, neste sentido, a poesia é uma das formas que permite às pessoas privadas da liberdade de combater os efeitos desumanos do encarceramento e, por isso, uma estratégia de resistência (Alexander, 2011; Pompa, 2011).

\section{Considerações finais}

A intenção de destacar os poemas-testemunho destas pessoas em reclusão deve ser entendida a partir da necessidade de se escutar as suas vozes para o estudo dos discursos ocultos do meio prisional. O abrir espaço para que as suas palavras sejam ouvidas permite combater os processos de silenciamento de que estas pessoas são alvo, contribuindo para a reconfiguração das suas experiências prisionais, e convidando à transformação do tecido social ao espoletar uma reflexão sobre os sistemas de opressão social.

Neste sentido, procurou-se demonstrar como a pesquisa poética pode constituir uma importante metodologia para a desconstrução do discurso prisional, uma vez que os poemas abrem linhas de fuga que ajudam a problematizar e a desconstruir as relações de poder, de violência e de resistência que coexistem intramuros. Como vimos, uma das formas de as alcançar e descodificar pode ser através da subjetividade - por vezes necessária - e, especialmente por isto, é que se torna importante o recurso a outras técnicas metodológicas de forma a corroborar a potencialidade da pesquisa poética e a afirmar o seu carácter multidisciplinar. As principais reticências colocadas a esta metodologia, de pouca expressão nas ciências sociais e humanas, prendem-se com a sua qualidade e validade. Isto leva-nos a pensar nas dificuldades impostas pela ortodoxia científica que, apesar da crescente importância atribuída à interdisciplinaridade, ainda é muito presente no mundo académico. Relativamente ao critério da qualidade foram levantadas duas questões no segundo andamento, dizendo uma respeito à relação entre a qualidade dos poemas e a pesquisa, e outra às capacidades do/a investigador/a para a realizar. Respondo à primeira com uma pergunta: quem diz que um poema é bom ou não? E com isto reitero a importância da poesia em quebrar padrões hegemónicos e promover saberes outros. Poderia responder à segunda questão do mesmo modo, mas o que me 
parece realmente relevante do ponto de vista do/a investigador/a é aquilo que Lave (2015) denomina de aprendizagem como/na prática, isto é, a ideia de uma aprendizagem enquanto processo que se desenvolve ao longo da prática.

Tendo em conta as minhas experiências com projetos em contexto prisional, e sendo este um meio em que facilmente se erguem muros que restringem a nossa ação, esta noção de aprendizagem como/na prática é especialmente significativa, requerendo uma constante capacidade anfíbia do/a dinamizador/a ou investigador/a (Rodríguez Garavito, 2015)..

Para terminar, sublinhe-se que os poemas-testemunho das pessoas em reclusão revelam o que potencialmente existe de comum entre todos/as nós, de um lado e do outro daqueles muros (Johnson e Chernoff, 2002).

\section{Referências bibliográficas}

A EQUI (2013), Poesia há. Solta!, Coimbra: A Equi.

ALEXANDER, Buzz (2011), "A Piece of the Reply: The Prison Creative Arts Project and Practicing Resistance", in Stephen John Hartnett (org.), Challenging the prison-industrial complex: activism, arts, and educational alternatives, Urbana, University of Illinois Press, 149- 180.

ANDREWS, Bruce (2001), "The Poetics of $\mathrm{L}=\mathrm{A}=\mathrm{N}=\mathrm{G}=\mathrm{U}=\mathrm{A}=\mathrm{G}=\mathrm{E}$ ”, disponível em: http://www. ubu.com/papers/andrews.html [consultado em: 10/02/2016]

BECKER, Howard (2010), Falando da sociedade: ensaios sobre as diferentes maneiras de representar o social, Rio de Janeiro, J. Zahar.

BERNSTEIN, Charles (1997), "A-poética", Revista Crítica de Ciências Sociais, n. 47:101-22.

BISHOP, Emily; WILLIS, Karen (2014), "Hope is that fiery feeling": Using Poetry as Data to Explore the Meanings of Hope for Young People", Forum Qualitative Sozialforschung/ Forum: Qualitative Social Research, vol. 15, disponível em: http://www.qualitative-research. net/index.php/fqs/article/view/2013 [consultado em: 10/03/2016].

BLOMMAERT, Jan (2005), Discourse: a critical introduction. Key topics in sociolinguistics, New York, Cambridge University Press.

CAPINHA, Graça (1997), "Ficções Credíveis no Campo da(s) Identidade(s): a poesia dos emigrantes portugueses no Brasil", Revista Crítica de Ciências Sociais, n. 48 (Junho), 103-146.

CREWE, Ben (2009), The prisoner society: power, adaptation, and social life in an English prison. Clarendon studies in criminology, Oxford, New York, Oxford University Press.

DELEUZE, Gilles, e GUATTARI, Félix (1986), Kafka: Toward a Minor Literature. Theory and History of Literature, v. 30. Minneapolis, University of Minnesota Press.

FAULKNER, Sandra (2009), Poetry as method: reporting research through verse. Developing qualitative inquiry, v. 6, Walnut Creek, CA, Left Coast Press.

FONSECA, Teresa (2010), Essa Marca Que Eu Tenho Na Língua. O Papel Da Escrita Criativa Na Reinserção Social: Um Estudo De Caso, Mestrado, Coimbra: Faculdade de Letras da Universidade de Coimbra.

FORCHÉ, Ed (1993), “Twentieth-Century Poetry of Witness: A column”, The American Poetry Review, 22 (2):9-16.

FOUCAULT, Michel (2008), Surveiller et punir: naissance de la prison, Collection TEL, Paris, Gallimard.

(2010), Nascimento da biopolítica, Lisboa, Edições 70. 
FURMAN, Rich; LANGER, Carol; DAVIS, Christine; GALLARDO, Heather; KULKARNI, Shanti (2007), "Expressive, Research and Reflective Poetry as Qualitative Inquiry: A Study of Adolescent Identity”, Qualitative Research, 7 (3):301-315 [Online], disponível em: https:// doi.org/10.1177/1468794107078511 [consultado em: 10/04/2016].

GALVIN, Kathleen, e PRENDERGAST, Monica (2016), Poetic Inquiry II: Seeing, Caring, Understanding ndUsing Poetry as and for Inquiry, Rotterdam, Sense Publishers. http:// public.eblib.com/choice/publicfullrecord.aspx? $\mathrm{p}=4202039$.

GOFFMAN, Erving (1961), Asylums - Essays on the Social Situation of Mental Patients and Other Inmates, New York, Anchor Books.

GONÇALVES, José Eduardo, ed. (2017), Mulheres Guerreiras / A Caminho da Liberdade, Porto, Santa Casa da Misericórdia do Porto.

GRANJA, Rafaela (2017), Para cá e para lá dos muros - Negociar relações familiares durante a reclusão,Porto, Edições Afrontamento.

HARTNETT, Stephen (2003), Incarceration nation: investigative prison poems of hope and terror. Crossroads in qualitative inquiry. Walnut Creek, CA, AltaMira Press.

JOHNSON, Robert, CHERNOFF, Nina (2002), “Opening a vein": Inmate poetry and the prison experience”, in The prison journal, 82 (2):141-167 [Online], disponível em: http://journals. sagepub.com/doi/abs/10.1177/003288550208200201 [consultado em: 10/02/2017].

KINSELLA, Anne (2006), "Poetic resistance: Juxtaposing personal and professional discursive constructions in a practice context", in Journal of the Canadian Association for Curriculum Studies, 4 (1):35-49 [Online], disponível em: http://jcacs.journals.yorku.ca/index.php/jcacs/ article/viewFile/16994/15796 [consultado em: 10/10/2016].

KRISTEVA, Julia (1980), Desire in Language: A Semiotic Approach to Literature and Art. European Perspectives, New York: Columbia Univ. Press.

LAHMAN, Maria; GEIST, Monica; RODRIGUEZ, Katrina; GRAGLIA, Pamela; RICHARD, Veronica; SCHENDEL, Roland (2010), "Poking Around Poetically: Research, Poetry, and Trustworthiness", in Qualitative Inquiry, 16 (1):39-48 [Online], disponível em: https://doi. org/10.1177/1077800409350061 [consultado em:10/10/2016].

(2011), "(Re) Forming research poetry", in Qualitative inquiry, 17 (9):887-896 [online], disponível em http://journals.sagepub.com/doi/abs/10.1177/1077800411423219?jo urnalCode=qixa [consultado em: 10/10/2016].

LAVE, Jean (2015), “Aprendizagem como/na prática”, Horizontes Antropológicos, 21 (44):3747 [Online], disponível em: https://doi.org/10.1590/S0104-71832015000200003 [consultado em: 10/10/2016].

LEAVY, Patricia (2015) Method meets art: arts-based research practice. Second edition. New York ; London: The Guilford Press.

LECERCLE, Jean-Jacques (1990), The violence of language, London ; New York: Routledge.

LEGGO, Carl (2008), "Astonishing silence: Knowing in Poetry”, in Gary Knowles e Ardra Cole (org.), Handbook of the arts in qualitative research: perspectives, methodologies, examples, and issues, Los Angeles, Sage Publications, 165-174.

MANSO, Ana (2016), Condição juvenil e trajetórias de deriva: rotas desviantes em contexto urbano, Doutoramento, Porto, Faculdade de Psicologia e Ciências da Educação da Universidade do Porto.

ORR, David (2008), “The Politics of Poetry”, in Poetry, 192 (4):409-418 [Online], disponível em: https://www.poetryfoundation.org/poetrymagazine/articles/69080/the-politics-of-poetry [consultado em:10/10/2016].

PARINI, Jay (2009), Why Poetry Matters, New Haven, Conn, London, Yale University Press.

PIIRTO, Jane (2002), “The Question of Quality and Qualifications: Writing Inferior Poems as Qualitative Research", in International Journal of Qualitative Studies in Education, 15 
(4):431-445 [Online], disponível em: https://doi.org/10.1080/09518390210145507 [consultado em: 20/10/2016].

PILLAY, Daisy; PITHOUSE-MORGAN, Kathleen; NAICKER, Inbanathan (2017), “SelfKnowledge Creation Through Collective Poetic Inquiry: Cultivating Productive Resistance as University Academics", Cultural Studies Critical Methodologies [Online], disponível em: http://journals.sagepub.com/doi/abs/10.1177/1532708617706118 [consultado em: 10/10/2016].

POMPA, Lori (2011), "Breaking Down the Walls: Inside-Out Learning and the Pedagogy of Transformation", in Stephen John Hartnett (org.), Challenging the prison-industrial complex: activism, arts, and educational alternatives, Urbana: University of Illinois Press, 253-272.

PRENDERGAST, Monica (2013), "Running around with Inmates, Maps and Swords: A Reflective Poetic-Narrative Autoethnography of a Prison Theatre Production", in Research in Drama Education: The Journal of Applied Theatre and Performance, 18 (3), 313-323 [Online], disponível em: https://doi.org/10.1080/13569783.2013.810927 [consultado em:10/10/2016].

PRENDERGAST, Monica; LEGGO, Carl; SAMESHIMA, Pauline (2009), Poetic Inquiry: Vibrant Voices in the Social Sciences, Rotterdam, Boston, Sense Publishers.

RAPPORT, Frances; HARTHILL, Graham (2012),"Crossing disciplines with ethnographic poetic representation", in Creative Approaches to Research, 5 (2), 11-25 [Online], disponível em: http://creativeapproachestoresearch.net/wp-content/uploads/CAR5_21.pdf [consultado em: 10/10/2016].

RHODES, Lisa (2002), "Poetry and a prison writing program: A mentor's narrative report", in Journal of Poetry Therapy, 15 (3), 163-168 [Online], disponível em: https://link.springer. com/article/10.1023/A:1019752229104 [consultado em:10/10/2016].

RHODES, Lorna (2001), "Toward an Anthropology of Prisons", in Annual Review of Anthropology, n. 30, 65-83 [Online], disponível em: http://www.annualreviews.org/ doi/10.1146/annurev.anthro.30.1.65 [consultado em: 10/10/2016].

RICHARDSON, Laurel (1993), "Poetics, Dramatics, and Transgressive Validity: The Case of the Skipped Line”, in The Sociological Quarterly, 34 (4):695-710 [Online] disponível em: http:// www.metanoia.ac.uk/media/1528/richardson-1-1993-poetics-dramatics-and-transgressive-validity.pdf [consultado em: 10/10/2016].

___(2002),"Writing sociology», in Cultural Studies - Critical Methodologies, 2 (3), 414-422 [Online], disponível em: http://journals.sagepub.com/doi/abs/10.1177/153270860200200311 [consultado em: 10/10/2016].

RODRÍGUEZ GARAVITO, César (2015), Human Rights in Minefields: Extractive Economies, Environmental Conflicts, and Social Justice in the Global South, Bogotá, Ediciones Antropos.

SCOTT, James (1990), Domination and the arts of resistance: hidden transcripts, New Haven, Yale University Press.

SHAPIRO, Johanna (2004), "Can Poetry Be Data? Potential Relationships Between Poetry and Research”, in Families, Systems, \& Health, 22 (2), 171-177 [Online], disponível em: https:// doi.org/10.1037/1091-7527.22.2.171 [consultado em: 10/10/2016].

SHIDMEHR, Nilofar (2014), "Poetic Inquiry and Its Lyrical Potential for Research", in $e d u$ cation, 20 (2),12-20, [Online], disponível em: http://ineducation.ca/ineducation/article/ view/180/661 [consultado em: 10/10/2016].

SJOLLEMA, Sandra D; BILOTTA, Neil (2016), "The raw and the poignant: using community poetry in research", in Journal of Poetry Therapy, 30 (1), 17-32 [Online], disponível em: http://www.tandfonline.com/doi/abs/10.1080/08893675.2016.1256466? journalCode=t jpt20 [consultado em: 20/12/2016]. 